\title{
Plasma Adiponectin and Hepatocellular Carcinoma Survival Among Patients Without Liver Transplantation
}

\author{
JING SHEN ${ }^{1,2}$, CHIH-CHING YEH ${ }^{1,3}$, QIAO WANG ${ }^{1}$, IRINA GURVICH ${ }^{1}$, \\ ABBY B. SIEGEL ${ }^{2,4}$ and REGINA M. SANTELLA ${ }^{1,2}$ \\ ${ }^{1}$ Departments of Environmental Health Sciences, \\ Mailman School of Public Health, Columbia University, New York, NY, U.S.A.; \\ ${ }^{2}$ Herbert Irving Comprehensive Cancer Center, Columbia University, New York, NY, U.S.A.; \\ ${ }^{3}$ School of Public Health, College of Public Health and Nutrition, \\ Taipei Medical University, Taipei, Taiwan, R.O.C.; \\ ${ }^{4}$ Department of Medicine, College of Physicians and Surgeons, \\ Columbia University Medical Center, New York, NY, U.S.A.
}

\begin{abstract}
Aim: To investigate the levels of leptin and adiponectin in prediction of hepatocellular carcinoma (HCC) survival among patients without liver transplantation. Materials and Methods: We measured pretreatment plasma leptin and adiponectin in 172 HCC cases who were prospectively followed-up over 7 years. Results: Gender, hepatitis $B$ virus $(H B V)$ and hepatitis $C$ virus (HCV) infection, high body mass index (BMI), diabetes mellitus (DM) history and Child-Pugh (CP) class were associated with leptin and adiponectin levels, while $\alpha$-fetoprotein (AFP) and presence of metastasis, being outside the Milan criteria and Barcelona clinic liver cancer (BCLC) stage, were significantly associated with liver transplantation and HCC survival. No significant association was observed for leptin or adiponectin and HCC survival in the overall group. In subgroup analyses among those without liver transplantation, we found significant associations between metastasis, Milan criteria, BCLC stage, hepatitis $B$ surface antigen (HBsAg) and HCC survival. When separately determining the Cox proportional hazard models and Kaplan-Meier survival curves by liver transplantation status, higher adiponectin was significantly associated with an increased hazard ratio $(H R)$ of death of 1.72 (95\% confidence interval $(C I)=1.12-2.64)$,
\end{abstract}

Current address of Abby B. Siegel: Merck \& Co., Kenilworth, NJ, U.S.A.

Correspondence to: Jing Shen, Department of Environmental Health Sciences, Mailman School of Public Health of Columbia University, 650 West 168th St., New York, NY 10032, U.S.A. Tel: +12123058158, e-mail: js2182@cumc.columbia.edu

Key Words: Adiponectin, leptin, HCC, survival, liver transplantation. i.e. poor survival among patients without liver transplantation. A multivariate Cox proportional hazard model, including adiponectin, CP class, presence of metastasis, tumor outside of Milan criteria, AFP and BCLC stage B/C parameters, also showed significant association with poor HCC survival (likelihood ratio test $p<0.0001$ ). No significant impact was observed for leptin on HCC survival regardless of liver transplantation status. Conclusion: Higher levels of plasma adiponectin may predict poor HCC survival among patients without liver transplantation.

In the United States, hepatocellular carcinoma (HCC) has become the fastest rising cause of cancer-related deaths (1). HCC prognosis is poor due to frequent intrahepatic spread and extrahepatic metastasis (2). The majority of HCC patients have no effective treatment due to advanced disease at the time of diagnosis. Although previous analyses have shown that tumor grade, stage at diagnosis, lymph/vascular invasion, number of primary tumors and tumor size are independent predictors for HCC survival $(3,4)$, these clinicopathological data were obtained from target tissues through invasive means that may impact their potential clinical application. The impact of favorable treatment (liver transplantation) on HCC prognosis has also not been excluded. Therefore, there is an urgent need to identify non-invasive biomarkers to accurately predict $\mathrm{HCC}$ prognosis especially for patients who are not suitable candidates for liver transplantation.

Leptin and adiponectin are two important adipokines secreted by adipose tissue; while liver tissue is adipose-rich (5). Leptin and adiponectin are known to regulate inflammation, tumor microenvironment and behavior (5). Changes in leptin and adiponectin levels have been associated with increased risks of breast (6-9), colorectal (10, 11), liver (12) and pancreatic (13) cancers. Results from 
HCC survival studies are contradictory on the role of leptin and adiponectin. Although basic mechanistic studies indicated that leptin acted to promote HCC proliferation, migration and invasion (5), clinical observation showed that higher leptin expression was associated with a better survival of HCC patients (14). Increased adiponectin has been associated with either favorable prognosis (15) or poor survival (16) for Asian HCC patients. A study of HCC tissues found that increased adiponectin significantly correlated with tumor size (17), indicating its possible role in prediction of poor prognosis. Our previous study also found that increased adiponectin level was significantly associated with poor HCC survival after adjusting for age, alcohol history, Child-Pugh (CP) class, stage and serum $\alpha$ fetoprotein (AFP) (4) but the potential impact of liver transplantation was not excluded.

In the current prospective study of HCC patients, we examined plasma leptin and adiponectin levels and their predictive role for HCC survival by liver transplantation status. In addition, we also evaluated the relationships between leptin and adiponectin levels and clinicopathological factors and the potential modification of HCC outcome.

\section{Materials and Methods}

Study subjects, epidemiologic/clinicopathological data and biospecimens' collection. A hospital-based prospective study was conducted at Columbia University Medical Center (CUMC) to recruit HCC patients ( $>18$ years older) from October 2008 to July 2014 who were followed up until March 2016. HCC patients either pathologically diagnosed or who met the criteria of the American Association for the Study of Liver Diseases (18) were recruited, while those who had any previous malignancy within the last 5 years, previously underwent liver transplantation, received any systemic cancer therapy, with $\mathrm{CP}$ class $\mathrm{C}$ disease or clinically significant ascites were excluded from the current study. Finally, a total of 172 HCC cases were eligible and analyzed for leptin and adiponectin. The research project was approved by the Columbia University Institutional Review Board and written informed consent was obtained from each participant.

All subjects completed a short, self-administered epidemiological questionnaire to collect demographic information on age, gender, race/ethnicity, place of birth of self and parents, education, occupation, active and passive smoking, alcohol consumption and family history of cancer, etc. A physical exam was performed to measure height, weight, waist and hip. Information on hepatitis B virus (HBV) and hepatitis $\mathrm{C}$ virus (HCV) infection and clinicopathological features including AFP levels, anti-viral treatment, cirrhotic status, Milan criteria, CP score, tumor stage, tumor size and survival status were obtained from the medical and pathological records. Treatments patients received during the followup period were also obtained from the medical records.

A $30 \mathrm{ml}$ fasting morning blood sample was collected at the time of enrollment and then processed by the Biomarkers Shared Resource of Herbert Irving Comprehensive Cancer Center at CUMC according to a standardized protocol. All samples were stored in $-80^{\circ} \mathrm{C}$ freezers connected to a telephone alarm system for future biomarker measurement.
Laboratory assays. Human leptin and adiponectin levels were determined in duplicate using commercial ELISA Kits (ThermoFisher Scientific, Camarillo, CA, USA). Leptin is a hormone produced by the $O B$ gene and secreted by adipocytes (19). Both natural and recombinant forms of leptin can be detected by the ELISA kit according to the manufacturer's protocols. A serial dilution of leptin (from 15.6 to $12,000 \mathrm{pg} / \mathrm{ml}$ ) was used to generate a standard curve. The intra- and inter-assay coefficients of variations (CVs) were $2.6 \%$, and $3.9 \%$, respectively. Similar processes were used to detect adiponectin with a standard curve covering from 0.5 to $32 \mathrm{ng} / \mathrm{ml}$. The intra- and inter-assay CVs were $4.0 \%$ and $6.3 \%$, respectively. Laboratory personnel were blinded to study hypotheses and outcomes. HBV surface antigen (HBsAg) and HCV (anti-HCV) status were determined by ELISA Kits (BioChain Institute Inc., Hayward, CA, USA) if not available from the medical records.

Statistical methods. The primary outcomes of interest were HCC survival status (dead vs. alive) and time from diagnosis to death (years) or date of last contact. Mortality data were obtained from medical records and confirmed with the National Death Index. The main predictors for outcomes were plasma leptin and adiponectin levels that were categorized by the median. Because we completed leptin and adiponectin measurements of all samples at two time points by different assays (140 for assay 1 and 32 for assay 2), we did not consider these two predictors as continuous variables in the statistical analysis. We separately dichotomized them into a single binary variable by the medians in each time point to exclude the potential batch effect. The medians of leptin were, respectively, 7.9 and $17.1 \mathrm{ng} / \mathrm{ml}$ for time-points 1 and 2; the medians of adiponectin were, respectively, 13.1 and $11.9 \mu \mathrm{g} / \mathrm{ml}$ for time points 1 and 2 . The covariates included age group ( $\geq 62.6 v s .<62.6$ years), gender (male $v s$. female), race/ethnicity (Non-Hispanic White $v s$. others), HBsAg (positive $v s$. negative) or anti-HCV (positive $v s$. negative), history of alcohol drinking (yes $v s$. no), cigarette smoking (ever vs. never), diabetes mellitus (DM) (yes $v s$. no), body mass index (BMI) $(\geq 30$ $\left.v s .<30 \mathrm{~kg} / \mathrm{m}^{2}\right)$, waist to hip ratio ( $\left.\geq 0.953 v s .<0.953\right)$, CP class (B vs. A), metastasis (yes vs. no), Barcelona Clinic Liver Cancer (BCLC) stage (B, C vs. 0, A), Milan criteria (outside vs. within), AFP levels ( $\geq 48 v s .<48 \mathrm{ng} / \mathrm{ml}$ ), liver transplantation (no vs. yes).

Categorical variables expressed as frequencies and percent values were analyzed by the Chi-squared test to show the associations between leptin, adiponectin and demographic and clinicopathological parameters, as well as with overall HCC survival and liver transplantation status. The univariate survival curves were calculated using the Kaplan-Meier method and the significance was determined by the log-rank test. In the model, death was the event and followup duration was the time variable. The follow-up period (years) for each patient was estimated starting from the date of HCC diagnosis to death or the date of last visit. Variables with significance $(p<0.05)$ from each univariate analysis were entered into the multivariate Cox proportional hazard model to estimate the overall prediction of death adjusted for other variables in the multivariate model. Starting with the full model, stepwise backward elimination was used as a variable selection procedure. A nominal $\alpha$ level of 0.20 was the cut-off for removing variables. Results are expressed as adjusted hazard ratios (aHR) with 95\% confidence interval (CI). Because liver transplantation is the most important favorable predictor for HCC survival, few variables can achieve significance in the Cox proportional hazard model if liver transplantation is included as a parameter. Thus, we also conducted additional subgroup analyses 
among those who could not undergo liver transplantation. All statistical analyses were performed using Statistical Analysis System 9.4 (SAS Institute, Cary, NC, USA).

\section{Results}

Categorized by the median of plasma leptin and adiponectin (Table I), high levels of leptin and adiponectin were more frequent among women (70 and $73 \%$, respectively) compared to men (44 and $47 \%$, respectively). HBV infection was associated with significantly lower adiponectin levels, while $\mathrm{HCV}$ infection was associated with higher adiponectin compared with virus-negative patients. Patients with high BMI and a history of DM had significantly increased leptin and decreased adiponectin compared to those without these risk factors. CP class B was the only clinicopathological feature associated with significantly elevated adiponectin levels $(p<0.0001)$.

We analyzed the covariates potentially correlated with liver transplantation and HCC survival (Table II). Several covariates, including higher AFP and presence of metastasis, being outside the Milan criteria and BCLC stage B or C, were significantly associated with lower percentages of liver transplantation (0$14 \%$ ) and poor HCC survival (higher mortality rates of 62 $90 \%$ ). No demographic factors or adipokines' markers were significantly associated with liver transplantation and overall HCC survival. Kaplan-Meier analyses showed no significant associations for leptin or adiponectin and overall HCC survival (data not shown). Additional subgroup analyses among those who could not undergo liver transplantation found that the presence of metastasis, being outside the Milan criteria, BCLC stage $\mathrm{B}$ or $\mathrm{C}$ and HBsAg-negative, were significantly associated with poor survival. Higher leptin and adiponectin levels were associated with poor survival but did not achieve statistical significance (Table III).

We observed that the survival periods for HCC patients with or without liver transplantation were significantly different (47.2 vs. 13.9 months), indicating that liver transplantation is an independent predictor for HCC survival (3). Therefore, inclusion of this parameter in the Cox proportional hazard model may conceal the role of other variables. At the same time, many clinicopathological factors associated with HCC survival were also the determinants of a liver transplantation (Table II). Therefore, we separately determined the Cox proportional hazard models and KaplanMeier survival curves by the status of liver transplantation to exclude the potential impact of treatment. In the univariate Cox model, CP class B, metastasis, outside of Milan criteria, higher AFP and BCLC stage B or C were associated with significantly increased risk of death for HCC patients without liver transplantation; however, no significant increase was observed for patients undergoing liver transplantation (Table IV). Higher adiponectin levels were significantly associated with increased $\mathrm{HR}$ of death $(\mathrm{HR}=1.72,95 \% \mathrm{CI}=1.12-2.64)$ only for those without liver transplantation (Table IV and Figure 1), indicating it may be a predictor for poor HCC survival. Patients with high adiponectin had a short survival time of 18.4 months, whereas patients with a low adiponectin survived 23.7 months, although this difference did not achieve statistical significance $(p=0.092)$. In the multivariate Cox proportional hazard model that included the above six parameters, the overall likelihood ratio test showed a significant $p$-value of $<0.0001$ (Table V) among those without liver transplantation after adjusting for other covariates. Only high AFP level $(\geq 48.0 \mathrm{ng} / \mathrm{ml})$ was associated with a significantly poorer $\mathrm{HCC}$ survival $(\mathrm{HR}=1.70,95 \% \mathrm{CI}=1.04-$ 2.76). Other individual factors, including adiponectin, did not show statistical significance. Plasma leptin level was not significantly associated with HCC survival regardless of treatment status (data not shown).

\section{Discussion}

In this prospective follow-up study (median follow-up time of 14 months, maximum 84 months), we found that high adiponectin levels were associated with shorter survival time than lower levels and may predict poor survival but only among patients without liver transplantation (Figure 1 and Table IV). In combination with a panel of clinicopathological factors, including CP class, metastasis status, Milan criteria, AFP, BCLC stage and adiponectin, the multivariate Cox proportional hazards model displayed a significant association with HCC survival among the same subgroup of non-transplant patients (likelihood ratio test $p<0.0001$, Table V). These data suggest that addition of biomarkers may enhance the accurate prediction of survival among HCC patients without a liver transplantation, who usually have a poor prognostic outcome.

Our previous study found that increased adiponectin level was significantly associated with an overall poorer HCC survival, but had a short follow-up period (median=8 months) (4) and the impact of liver transplantation on HCC survival was not excluded (3). In the current longer time follow-up study, we confirmed the significant association of higher adiponectin with poor HCC survival among patients without liver transplantation, but not in patients with transplantation, suggesting the predictive role of adiponectin in a specific HCC subgroup. Although many previous studies suggested an inverse relationship between adiponectin and risk of several cancer types, as well as poor cancer prognosis at lower levels (20), results from HCC studies appear to be the reverse or heterogeneous, i.e. higher adiponectin levels may be associated with increased risk of $\operatorname{HCC}(12,20,21)$, advanced liver disease $(22,23)$ and predict worse $(4,16)$ or favorable prognosis (15) for HCC patients. Therefore, the role of adiponectin in carcinogenesis and progression may be variable by cancer type. 
Table I. Comparison of plasma leptin and adiponectin levels by demographic and clinicopathological characteristics.

\begin{tabular}{|c|c|c|c|c|c|c|}
\hline \multirow[t]{2}{*}{ Variables } & \multicolumn{2}{|c|}{ Leptin (ng/ml), No (\%) } & \multirow[t]{2}{*}{$p$-Value } & \multicolumn{2}{|c|}{ Adiponectin $(\mu \mathrm{g} / \mathrm{ml})$, No $(\%)$} & \multirow[t]{2}{*}{$p$-Value } \\
\hline & $<$ Median & $\geq$ Median & & $<$ Median & $\geq$ Median & \\
\hline \multicolumn{7}{|l|}{ Age group } \\
\hline$<62.6$ years & $42(48.8)$ & $44(51.2)$ & & $46(53.5)$ & $40(46.5)$ & \\
\hline$\geq 62.6$ years & $41(47.7)$ & $45(52.3)$ & 0.879 & $40(46.5)$ & $46(53.5)$ & 0.360 \\
\hline \multicolumn{7}{|l|}{ Gender } \\
\hline Female & $11(29.7)$ & $26(70.3)$ & & $10(27.0)$ & $27(73.0)$ & \\
\hline Male & $72(53.3)$ & $63(46.7)$ & 0.011 & $76(56.3)$ & $59(43.7)$ & 0.002 \\
\hline \multicolumn{7}{|l|}{ Race/ethnicity } \\
\hline Non-Hispanic White & $34(41.5)$ & $48(58.5)$ & & $44(53.7)$ & $38(46.3)$ & \\
\hline Others & $49(54.4)$ & $41(45.6)$ & 0.089 & $42(46.7)$ & $48(53.3)$ & 0.359 \\
\hline \multicolumn{7}{|c|}{ Hepatitis B virus infection } \\
\hline Negative & $65(45.5)$ & $78(54.5)$ & & $66(46.2)$ & $77(53.8)$ & \\
\hline Positive & $18(62.1)$ & $11(37.9)$ & 0.103 & $20(68.9)$ & $9(31.1)$ & 0.025 \\
\hline \multicolumn{7}{|c|}{ Hepatitis $\mathrm{C}$ virus infection } \\
\hline Negative & $30(41.7)$ & $42(58.3)$ & & $46(63.9)$ & $26(36.1)$ & \\
\hline Positive & $53(53.0)$ & $47(47.0)$ & 0.142 & $40(40.0)$ & $60(60.0)$ & 0.002 \\
\hline \multicolumn{7}{|l|}{ Alcohol drinking history } \\
\hline No & $62(50.0)$ & $62(50.0)$ & & $62(50.0)$ & $62(50.0)$ & \\
\hline Yes & $21(43.8)$ & $27(56.2)$ & 0.462 & $24(50.0)$ & $24(50.0)$ & 1.000 \\
\hline \multicolumn{7}{|l|}{ Cigarette smoking } \\
\hline Never & $31(48.4)$ & $33(51.6)$ & & $31(48.4)$ & $33(51.6)$ & \\
\hline Ever & $48(48.0)$ & $52(52.0)$ & 0.956 & $50(50.0)$ & $50(50.0)$ & 0.845 \\
\hline \multicolumn{7}{|l|}{ Diabetes mellitus history } \\
\hline No & $55(56.7)$ & $42(43.3)$ & & $44(45.4)$ & $53(54.6)$ & \\
\hline Yes & $28(37.3)$ & $47(62.7)$ & 0.012 & $42(56.0)$ & $33(44.0)$ & 0.166 \\
\hline \multicolumn{7}{|c|}{ Body mass index at enrollment $\left(\mathrm{kg} / \mathrm{m}^{2}\right)$} \\
\hline$<30$ & $42(80.8)$ & $10(19.2)$ & & $19(36.5)$ & $33(63.5)$ & \\
\hline$\geq 30.0$ & $34(32.4)$ & $71(67.6)$ & $<0.0001$ & $58(55.2)$ & $47(44.8)$ & 0.027 \\
\hline \multicolumn{7}{|l|}{ Waist to hip ratio } \\
\hline$<0.953$ & $42(55.3)$ & $34(44.7)$ & & $36(47.4)$ & $40(52.6)$ & \\
\hline$\geq 0.953$ & $31(40.3)$ & $46(59.7)$ & 0.063 & $40(51.9)$ & $37(48.1)$ & 0.571 \\
\hline \multicolumn{7}{|l|}{$\alpha$-fetoprotein $(\mathrm{ng} / \mathrm{ml})$} \\
\hline$<48$ & $37(43.5)$ & $48(56.5)$ & & $41(48.2)$ & $44(51.8)$ & \\
\hline$\geq 48$ & $46(52.9)$ & $41(47.1)$ & 0.220 & $45(51.7)$ & $42(48.3)$ & 0.647 \\
\hline \multicolumn{7}{|l|}{ Child-Pugh class } \\
\hline A & $52(49.1)$ & $54(50.9)$ & & $70(66.0)$ & $36(34.0)$ & \\
\hline $\mathrm{B}$ & $30(46.2)$ & $35(53.8)$ & 0.712 & $16(24.6)$ & $49(75.4)$ & $<0.0001$ \\
\hline \multicolumn{7}{|l|}{ Metastasis } \\
\hline Negative & $70(49.0)$ & $73(51.0)$ & & $71(49.7)$ & $72(50.4)$ & \\
\hline Positive & $10(52.6)$ & $9(47.4)$ & 0.763 & $10(52.6)$ & $9(47.4)$ & 0.807 \\
\hline \multicolumn{7}{|l|}{ Milan criteria } \\
\hline Within & $28(43.1)$ & $37(56.9)$ & & $34(52.3)$ & $31(47.7)$ & \\
\hline Outside & $55(51.4)$ & $52(48.6)$ & 0.289 & $52(48.6)$ & $55(51.4)$ & 0.637 \\
\hline Barcelona clinic liver c & & & & & & \\
\hline $0, \mathrm{~A}$ & $30(48.4)$ & $32(51.6)$ & & $30(48.4)$ & $32(51.6)$ & \\
\hline $\mathrm{B}, \mathrm{C}$ & $53(48.2)$ & $57(51.8)$ & 0.979 & $56(50.9)$ & $54(49.1)$ & 0.751 \\
\hline Cancer antigen 19-9 (L & & & & & & \\
\hline$<38.0$ & $36(43.9)$ & $46(56.1)$ & & $45(54.9)$ & $37(45.1)$ & \\
\hline$\geq 38.0$ & $46(52.3)$ & $42(47.7)$ & 0.275 & $40(45.5)$ & $48(54.5)$ & 0.220 \\
\hline Liver transplantation & & & & & & \\
\hline No & $70(51.9)$ & $65(48.1)$ & & $68(50.4)$ & $67(49.6)$ & \\
\hline Yes & $13(35.1)$ & $24(64.9)$ & 0.071 & $18(48.7)$ & $19(51.43)$ & 0.853 \\
\hline
\end{tabular}

We found the association of higher adiponectin levels and poorer HCC survival only in HCC patients without liver transplantation; these patients usually have more advanced disease and may have severe weight loss and cancer-related cachexia. This is consistent with our observation that HCC patients with lower BMI more 
Table II. Demographic and clinicopathological factors and leptin and adiponectin levels in association with hepatocellular carcinoma liver transplantation and survival.

\begin{tabular}{|c|c|c|c|c|c|c|}
\hline \multirow[t]{2}{*}{ Variables } & \multicolumn{2}{|c|}{ Liver transplantation, No (\%) } & \multirow[t]{2}{*}{$p$-Value } & \multicolumn{2}{|c|}{ Survival status, No (\%) } & \multirow[t]{2}{*}{$p$-Value } \\
\hline & No & Yes & & Alive & Dead & \\
\hline \multicolumn{7}{|l|}{ Age group } \\
\hline$<62.6$ years & $63(73.3)$ & $23(26.7)$ & & $42(48.8)$ & $44(51.2)$ & \\
\hline$\geq 62.6$ years & $72(83.7)$ & $14(16.3)$ & 0.095 & $36(41.9)$ & $50(58.1)$ & 0.358 \\
\hline \multicolumn{7}{|l|}{ Gender } \\
\hline Female & $30(81.1)$ & 7 (18.9) & & $16(43.2)$ & $21(56.8)$ & \\
\hline Male & $105(77.8)$ & $30(22.2)$ & 0.665 & $62(45.9)$ & $73(54.1)$ & 0.772 \\
\hline \multicolumn{7}{|l|}{ Race/ethnicity } \\
\hline Non-Hispanic White & $63(76.8)$ & $19(23.2)$ & & $35(42.7)$ & $47(57.3)$ & \\
\hline Others & $72(80.0)$ & $18(20.0)$ & 0.613 & $43(47.8)$ & $47(52.2)$ & 0.503 \\
\hline \multicolumn{7}{|c|}{ Hepatitis B virus infection } \\
\hline Negative & $111(77.6)$ & $32(22.4)$ & & $62(43.4)$ & $81(56.6)$ & \\
\hline Positive & $24(82.8)$ & $5(17.2)$ & 0.539 & $16(55.2)$ & $13(44.8)$ & 0.244 \\
\hline \multicolumn{7}{|c|}{ Hepatitis $C$ virus infection } \\
\hline Negative & $59(81.9)$ & $13(18.6)$ & & $30(41.7)$ & $42(58.3)$ & \\
\hline Positive & $76(76.0)$ & $24(24.0)$ & 0.349 & $48(48.0)$ & $52(52.0)$ & 0.411 \\
\hline \multicolumn{7}{|l|}{ Alcohol drinking history } \\
\hline No & $100(80.7)$ & $24(19.3)$ & & $52(41.9)$ & $72(58.1)$ & \\
\hline Yes & $35(72.9)$ & $13(27.1)$ & 0.269 & $26(54.2)$ & $22(45.8)$ & 0.148 \\
\hline \multicolumn{7}{|l|}{ Cigarette smoking } \\
\hline Never & $52(81.3)$ & $12(18.7)$ & & $28(43.8)$ & $36(56.2)$ & \\
\hline Ever & $77(77.0)$ & $23(23.0)$ & 0.517 & $46(46.0)$ & $54(54.0)$ & 0.778 \\
\hline \multicolumn{7}{|l|}{ Diabetes mellitus history } \\
\hline No & $72(74.2)$ & $25(25.8)$ & & $47(48.5)$ & $50(51.5)$ & \\
\hline Yes & $63(84.0)$ & $12(16.0)$ & 0.122 & $31(41.3)$ & $44(58.7)$ & 0.352 \\
\hline \multicolumn{7}{|c|}{ Body mass index at enrollment $\left(\mathrm{kg} / \mathrm{m}^{2}\right)$} \\
\hline$<30$ & $44(84.6)$ & $8(15.4)$ & & $25(48.1)$ & $27(51.9)$ & \\
\hline$\geq 30.0$ & $78(74.3)$ & $27(25.7)$ & 0.143 & $46(43.8)$ & $59(56.2)$ & 0.613 \\
\hline \multicolumn{7}{|l|}{ Waist to hip ratio } \\
\hline$<0.953$ & $60(78.9)$ & $16(21.1)$ & & $37(48.7)$ & $39(51.3)$ & \\
\hline$\geq 0.953$ & $59(76.6)$ & $18(23.4)$ & 0.729 & $32(41.6)$ & $45(58.4)$ & 0.376 \\
\hline \multicolumn{7}{|l|}{$\alpha$-fetoprotein $(\mathrm{ng} / \mathrm{ml})$} \\
\hline$<48$ & $58(68.2)$ & $27(31.8)$ & & $49(57.7)$ & $36(42.4)$ & \\
\hline$\geq 48$ & $77(88.5)$ & $10(11.5)$ & 0.001 & $29(33.3)$ & $58(66.7)$ & 0.001 \\
\hline \multicolumn{7}{|l|}{ Child-Pugh class } \\
\hline A & $82(77.4)$ & $24(22.6)$ & & $52(49.1)$ & $54(50.9)$ & \\
\hline $\mathrm{B}$ & $52(80.0)$ & $13(20.0)$ & 0.684 & $25(38.5)$ & $40(61.5)$ & 0.176 \\
\hline \multicolumn{7}{|l|}{ Metastasis } \\
\hline No & $107(74.8)$ & $36(25.2)$ & & $73(51.1)$ & $70(48.9)$ & \\
\hline Yes & $19(100.0)$ & $0(0.0)$ & 0.013 & $2(10.5)$ & $17(89.5)$ & 0.001 \\
\hline \multicolumn{7}{|l|}{ Milan criteria } \\
\hline Within & $39(60.0)$ & $26(40.0)$ & & $44(67.7)$ & $21(32.3)$ & \\
\hline Outside & $96(89.7)$ & $11(10.3)$ & $<0.0001$ & $34(31.8)$ & $73(68.2)$ & $<0.0001$ \\
\hline Barcelona clinic liver ca & & & & & & \\
\hline $0, \mathrm{~A}$ & $40(64.5)$ & $22(35.5)$ & & $41(66.1)$ & $21(33.9)$ & \\
\hline $\mathrm{B}, \mathrm{C}$ & $95(86.4)$ & $15(13.6)$ & 0.001 & $37(33.6)$ & $73(66.4)$ & $<0.0001$ \\
\hline Leptin (ng/ml) & & & & & & \\
\hline$<$ Median & $70(84.3)$ & $13(15.7)$ & & $37(44.6)$ & $46(55.4)$ & \\
\hline$\geq$ Median & $65(73.0)$ & $24(27.0)$ & 0.071 & $41(46.1)$ & $48(53.9)$ & 0.845 \\
\hline Adiponectin $(\mu \mathrm{g} / \mathrm{ml})$ & & & & & & \\
\hline$<$ Median & $68(79.1)$ & $18(20.9)$ & & $42(48.8)$ & $44(51.2)$ & \\
\hline$\geq$ Median & 67 (77.9) & $19(22.1)$ & 0.853 & $36(41.9)$ & $50(58.1)$ & 0.358 \\
\hline
\end{tabular}

frequently had higher adiponectin $(63.5 \%)$ compared to those with higher BMI $(44.8 \%$, Table I). Several previous studies also consistently found that adiponectin levels were inversely correlated with BMI $(17,24)$. Similarly, we also found that patients of $\mathrm{CP}$ class B more frequently had increased adiponectin (75.4\%) compared to class A $(34.0 \%$, 
Table I). Therefore, the higher adiponectin levels observed in poorer survivors may be compensatory for weight loss and cachexia in advanced HCC patients without liver transplantation. Whether the increased adiponectin is transient or stable during cancer progression needs further investigation to clarify the correlation of adiponectin with HCC survival.

The molecular mechanisms by which increased adiponectin is associated with poorer HCC survival are not fully understood but a few biological and functional studies provide supporting evidence. The increased adiponectin in HCC may arise from worsening liver function (elevated albumin and alkaline phosphatase (ALP)) (16) as adiponectin levels reflect the severity of liver fibrosis (22), cirrhosis (23) and tumor size (17), which are correlated with consequent poorer prognosis. An in vitro study observed that adiponectin significantly increased the proliferation rate of Hep-G2 and Hep-3B cells, as well as the numbers of $\mathrm{S}$ phase cells and 5bromo-2'-deoxyuridine (BrdU)-positive cells in a dosedependent manner (17). Ectopic overexpression of adiponectin increased proliferation, invasion, as well as the expression of downstream genes (cyclin D1 and $\beta$-catenin) in Hep3B and HepG2 cells (16). However, adiponectin also showed dual molecular functions of anti-inflammatory, proinflammatory, anti-apoptotic and apoptosis induction effects $(25,26)$. A deeper exploration of the functional networks in hepatocarcinogenesis and progression can help to further understand the complex role of adiponectin as a tumor suppressor or promoter.

In summary, our study has several strengths, including the prospective nature, long-term follow-up and the analysis of homogenous HCC patients without liver transplantation. Our data first demonstrate higher adiponectin level is associated with shorter survival time and that it may be a useful prognostic marker when integrated with 5 clinicopathological factors for a subgroup of HCC patients without treatment by liver transplantation. Important etiologic (BMI, HBV/HCV infection), pathological (AFP, CP class, metastasis, Milan criteria, BCLC stage) and treatment factors associated with liver transplantation or HCC survival should be considered in analyzing the role of prognostic biomarkers. It should be noted that the statistical power of the current study is limited due to the small sample size. The one time point measurement for adiponectin and leptin is another limitation. Further validation in a large HCC patients' cohort is warranted to add more convincing information to guide strategy development and implementation of precision medicine and improve HCC survival prediction and management.

\section{Conflicts of Interest}

The Authors declare that they have no potential conflicts of interest.
Table III. Demographic, clinicopathological factors and leptin, adiponectin markers in association with hepatocellular carcinoma survival among those without liver transplant.

\begin{tabular}{|c|c|c|c|}
\hline \multirow[t]{2}{*}{ Variables } & \multicolumn{2}{|c|}{ Survival status, No (\%) } & \multirow[t]{2}{*}{$p$-Value } \\
\hline & Alive & Dead & \\
\hline \multicolumn{4}{|l|}{ Age group } \\
\hline$<62.6$ years & $23(36.5)$ & $40(63.5)$ & \\
\hline$\geq 62.6$ years & $25(34.7)$ & $47(65.3)$ & 0.829 \\
\hline \multicolumn{4}{|l|}{ Gender } \\
\hline Female & $10(33.3)$ & $20(66.7)$ & \\
\hline Male & $38(36.2)$ & $67(63.8)$ & 0.773 \\
\hline \multicolumn{4}{|l|}{ Race/ethnicity } \\
\hline Non-Hispanic White & $17(27.0)$ & $46(73.0)$ & \\
\hline Others & $31(43.1)$ & $41(56.9)$ & 0.052 \\
\hline \multicolumn{4}{|c|}{ Hepatitis B virus infection } \\
\hline Negative & $35(31.5)$ & $76(68.5)$ & \\
\hline Positive & $13(54.2)$ & $11(45.8)$ & 0.036 \\
\hline \multicolumn{4}{|c|}{ Hepatitis $\mathrm{C}$ virus infection } \\
\hline Negative & $20(33.9)$ & $39(66.1)$ & \\
\hline Positive & $28(36.8)$ & $48(63.2)$ & 0.411 \\
\hline \multicolumn{4}{|l|}{ Alcohol drinking history } \\
\hline No & $33(33.0)$ & $67(67.0)$ & \\
\hline Yes & $15(42.9)$ & $20(57.1)$ & 0.294 \\
\hline \multicolumn{4}{|l|}{ Cigarette smoking } \\
\hline Never & $19(36.5)$ & $33(63.5)$ & \\
\hline Ever & $27(35.1)$ & $50(64.9)$ & 0.864 \\
\hline \multicolumn{4}{|l|}{ Diabetes mellitus history } \\
\hline No & $28(38.9)$ & $44(61.1)$ & \\
\hline Yes & $20(31.8)$ & $43(68.3)$ & 0.387 \\
\hline \multicolumn{4}{|l|}{$\begin{array}{l}\text { Body mass index at } \\
\text { enrollment }\left(\mathrm{kg} / \mathrm{m}^{2}\right)\end{array}$} \\
\hline$<30$ & $18(40.9)$ & $26(59.1)$ & \\
\hline$\geq 30.0$ & $25(32.1)$ & $53(67.9)$ & 0.325 \\
\hline \multicolumn{4}{|l|}{ Waist to hip ratio } \\
\hline$<0.953$ & $23(38.3)$ & $37(61.7)$ & \\
\hline$\geq 0.953$ & $17(28.8)$ & $42(71.2)$ & 0.272 \\
\hline \multicolumn{4}{|l|}{$\alpha$-fetoprotein $(\mathrm{ng} / \mathrm{ml})$} \\
\hline$<48$ & $26(44.8)$ & $32(55.2)$ & \\
\hline$\geq 48$ & $22(28.6)$ & $55(71.4)$ & 0.051 \\
\hline \multicolumn{4}{|l|}{ Child-Pugh class } \\
\hline A & $33(40.2)$ & $49(59.8)$ & \\
\hline $\mathrm{B}$ & $14(26.9)$ & $38(73.1)$ & 0.115 \\
\hline \multicolumn{4}{|l|}{ Metastasis } \\
\hline No & $44(41.1)$ & $63(58.9)$ & \\
\hline Yes & $2(10.5)$ & $17(89.5)$ & 0.011 \\
\hline \multicolumn{4}{|l|}{ Milan criteria } \\
\hline Within & 23. (59.0) & $16(41.0)$ & \\
\hline Outside & $25(26.0)$ & $71(74.0)$ & $<0.001$ \\
\hline \multicolumn{4}{|c|}{ Barcelona clinic liver cancer stage } \\
\hline $0, \mathrm{~A}$ & $23(57.5)$ & $17(42.5)$ & \\
\hline $\mathrm{B}, \mathrm{C}$ & $25(26.3)$ & $70(73.7)$ & 0.001 \\
\hline \multicolumn{4}{|c|}{ Cancer antigen 19-9 (U/ml) } \\
\hline$<38.0$ & $24(38.1)$ & $39(61.9)$ & \\
\hline$\geq 38.0$ & $23(32.9)$ & $47(67.1)$ & 0.528 \\
\hline Leptin (ng/ml) & & & \\
\hline$<$ Median & $26(37.1)$ & $44(62.9)$ & \\
\hline$\geq$ Median & $22(33.9)$ & $43(66.1)$ & 0.689 \\
\hline Adiponectin $(\mu \mathrm{g} / \mathrm{ml})$ & & & \\
\hline$<$ Median & $28(41.2)$ & $40(58.8)$ & \\
\hline$\geq$ Median & $20(29.9)$ & $47(70.1)$ & 0.169 \\
\hline
\end{tabular}




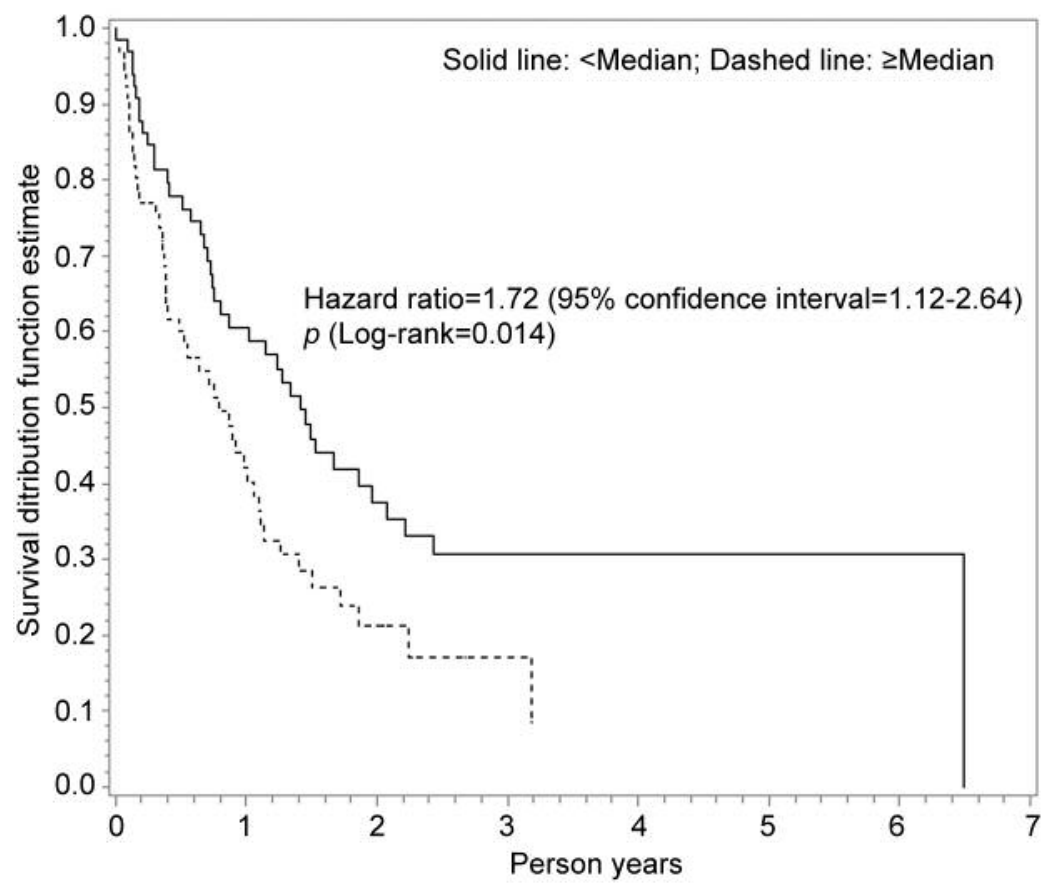

Figure 1. Kaplan-Meier analysis for adiponectin and overall survival among 135 hepatocellular carcinoma (HCC) patients without liver transplantation. Dashed line indicates plasma adiponectin levels $\geq$ Median, while solid line means adiponectin $<$ Median. The Kaplan-Meier analysis showed that HCC patients with higher adiponectin may be more likely to experience a worse overall survival $(H R=1.72,95 \% C I=1.12-2.64$, $p=0.014)$.

Table IV. Univariate Cox proportional hazards model for hepatocellular carcinoma survival by liver transplantation status.

\begin{tabular}{|c|c|c|c|c|c|c|c|}
\hline \multirow[t]{2}{*}{ Variable } & & \multicolumn{3}{|c|}{$\begin{array}{c}\text { No liver transplantation } \\
\qquad(\mathrm{N}=135)\end{array}$} & \multicolumn{3}{|c|}{$\begin{array}{l}\text { Liver transplantation } \\
\qquad(\mathrm{N}=37)\end{array}$} \\
\hline & & $\begin{array}{c}\text { Hazard } \\
\text { Ratio }\end{array}$ & $\begin{array}{l}95 \% \text { confidence } \\
\text { interval }\end{array}$ & $p$-Value & $\begin{array}{l}\text { Hazard } \\
\text { Ratio }\end{array}$ & $\begin{array}{l}95 \% \text { confidence } \\
\text { interval }\end{array}$ & $p$-Value \\
\hline Child-Pugh class & B vs. A & 1.84 & $1.20-2.82$ & 0.006 & 0.77 & $0.15-3.97$ & 0.751 \\
\hline Metastasis & Yes $v s$. No & 2.45 & $1.42-4.22$ & 0.001 & ND & ND & $\mathrm{ND}$ \\
\hline Milan criteria & Outside $v s$. within & 3.04 & $1.74-5.34$ & 0.0001 & 0.64 & $0.12-3.51$ & 0.611 \\
\hline$\alpha$-fetoprotein $(\mathrm{ng} / \mathrm{ml})$ & $\geq 48.0 \mathrm{vs} .<48.0$ & 2.17 & $1.39-3.40$ & 0.0007 & 2.37 & $0.53-10.69$ & 0.260 \\
\hline Barcelona clinic liver cancer stage & $\mathrm{B}, \mathrm{C} v s .0, \mathrm{~A}$ & 2.72 & $1.57-4.70$ & 0.0003 & 1.10 & $0.25-4.94$ & 0.899 \\
\hline Adiponectin $(\mu \mathrm{g} / \mathrm{ml})$ & $\geq$ Median vs. $<$ Median & 1.72 & $1.12-2.64$ & 0.014 & 0.67 & $0.15-3.01$ & 0.603 \\
\hline
\end{tabular}

Table V. Multivariate Cox proportional hazards model* for hepatocellular carcinoma patients without liver transplantation. Variable No liver transplantation $(N=135)$.

\begin{tabular}{|c|c|c|c|c|}
\hline & & Adjusted Hazard Ratio & $95 \%$ confidence interval & $p$-Value \\
\hline Child-Pugh class & B vs. A & 1.48 & $0.90-2.43$ & 0.121 \\
\hline Metastasis & Yes $v s$. No & 1.67 & $0.94-2.95$ & 0.080 \\
\hline Milan criteria & Outside $v s$. within & 1.78 & $0.93-3.41$ & 0.083 \\
\hline$\alpha$-fetoprotein $(\mathrm{ng} / \mathrm{ml})$ & $\geq 48.0 v s .<48.0$ & 1.70 & $1.04-2.76$ & 0.033 \\
\hline Barcelona clinic liver cancer stage & $\mathrm{B}, \mathrm{C} v s .0, \mathrm{~A}$ & 1.57 & $0.84-2.95$ & 0.162 \\
\hline Adiponectin $(\mu \mathrm{g} / \mathrm{ml})$ & $\geq$ Median vs. $<$ Median & 1.39 & $0.85-2.26$ & 0.190 \\
\hline
\end{tabular}

*Likelihood ratio test $p<0.0001$. 


\section{Acknowledgements}

This work is supported by NIH grants R01 ES005116 (RMS), P30 ES009089 (RMS), P30 CA013696 (RMS), R03 CA156629 (JS).

\section{References}

1 El Serag HB: Hepatocellular carcinoma. N Engl J Med 365: 1118-1127, 2011.

2 Lafaro KJ, Demirjian AN and Pawlik TM: Epidemiology of hepatocellular carcinoma. Surg Oncol Clin N Am 24: 1-17, 2015.

3 Njei B, Rotman Y, Ditah I and Lim JK: Emerging trends in hepatocellular carcinoma incidence and mortality. Hepatology 61: 191-199, 2015.

4 Siegel AB, Goyal A, Salomao M, Wang S, Lee V, Hsu C, Rodriguez R, Hershman DL, Brown RS Jr., Neugut AI, Emond J, Kato T, Samstein B, Faleck D and Karagozian R: Serum adiponectin is associated with worsened overall survival in a prospective cohort of hepatocellular carcinoma patients. Oncology 88: 57-68, 2015.

5 Deng T, Lyon CJ, Bergin S, Caligiuri MA and Hsueh WA: Obesity, Inflammation, and Cancer. Annu Rev Pathol 11: 421449, 2016.

6 Gross AL, Newschaffer CJ, Hoffman-Bolton J, Rifai N and Visvanathan K: Adipocytokines, inflammation, and breast cancer risk in postmenopausal women: a prospective study. Cancer Epidemiol Biomarkers Prev 22: 1319-1324, 2013.

7 Macis D, Guerrieri-Gonzaga A and Gandini S: Circulating adiponectin and breast cancer risk: a systematic review and metaanalysis. Int J Epidemiol 43: 1226-1236, 2014.

8 Ye J, Jia J, Dong S, Zhang C, Yu S, Li L, Mao C, Wang D, Chen $\mathrm{J}$ and Yuan G: Circulating adiponectin levels and the risk of breast cancer: a meta-analysis. Eur J Cancer Prev 23: 158-165, 2014.

9 Liu LY, Wang M, Ma ZB, Yu LX, Zhang Q, Gao DZ, Wang F and Yu ZG: The role of adiponectin in breast cancer: a metaanalysis. PLoS ONE 8: e73183, 2013.

10 Aleksandrova K, Jenab M, Bueno-de-Mesquita HB, Fedirko V, Kaaks R, Lukanova A, van Duijnhoven FJ, Jansen E, Rinaldi S, Romieu I, Ferrari P, Murphy N, Gunter MJ, Riboli E, Westhpal S, Overvad K, Tjonneland A, Halkjaer J, Boutron-Ruault MC, Dossus L, Racine A, Trichopoulou A, Bamia C, Orfanos P, Agnoli C, Palli D, Panico S, Tumino R, Vineis P, Peeters PH, Duell EJ, Molina-Montes E, Quiros JR, Dorronsoro M, Chirlaque MD, Barricarte A, Ljuslinder I, Palmqvist R, Travis RC, Khaw KT, Wareham N, Pischon T and Boeing H: Biomarker patterns of inflammatory and metabolic pathways are associated with risk of colorectal cancer: results from the European Prospective Investigation into Cancer and Nutrition (EPIC). Eur J Epidemiol 29: 261-275, 2014.

11 Otani K, Ishihara S, Yamaguchi H, Murono K, Yasuda K, Nishikawa T, Tanaka T, Kiyomatsu T, Hata K, Kawai K, Nozawa $\mathrm{H}$ and Watanabe $\mathrm{T}$ : Adiponectin and colorectal cancer. Surg Today 2016.

12 Song RR and Gu XL: Serum adiponectin levels may be associated with the pathogenesis of hepatocellular carcinoma. Tumour Biol 36: 2983-2992, 2015.
13 Stolzenberg-Solomon RZ, Newton CC, Silverman DT, Pollak M, Nogueira LM, Weinstein SJ, Albanes D, Mannisto S and Jacobs EJ: Circulating Leptin and Risk of Pancreatic Cancer: A Pooled Analysis From 3 Cohorts. Am J Epidemiol 182: 187-197, 2015.

14 Wang SN, Yeh YT, Yang SF, Chai CY and Lee KT: Potential role of leptin expression in hepatocellular carcinoma. J Clin Pathol 59: 930-934, 2006.

15 Shin E, Yu YD, Kim DS and Won NH: Adiponectin receptor expression predicts favorable prognosis in cases of hepatocellular carcinoma. Pathol Oncol Res 20: 667-675, 2014.

16 Wang SN, Yang SF, Tsai HH, Lee KT and Yeh YT: Increased adiponectin associated with poor survival in hepatocellular carcinoma. J Gastroenterol 49: 1342-1351, 2014.

17 Chen MJ, Yeh YT, Lee KT, Tsai CJ, Lee HH and Wang SN: The promoting effect of adiponectin in hepatocellular carcinoma. J Surg Oncol 106: 181-187, 2012.

18 Bruix J, Sherman M and American Association for the Study of Liver Diseases: Management of hepatocellular carcinoma: an update. Hepatology 53: 1020-1022, 2011.

19 Friedman JM and Halaas JL: Leptin and the regulation of body weight in mammals. Nature 395: 763-770, 1998.

20 Katira A and Tan PH: Evolving role of adiponectin in cancercontroversies and update. Cancer Biol Med 13: 101-119, 2016.

21 Aleksandrova K, Boeing H, Nothlings U, Jenab M, Fedirko V, Kaaks R, Lukanova A, Trichopoulou A, Trichopoulos D, Boffetta P, Trepo E, Westhpal S, Duarte-Salles T, Stepien M, Overvad K, Tjonneland A, Halkjaer J, Boutron-Ruault MC, Dossus L, Racine A, Lagiou P, Bamia C, Benetou V, Agnoli C, Palli D, Panico S, Tumino R, Vineis P, Bueno-de-Mesquita B, Peeters PH, Gram IT, Lund E, Weiderpass E, Quiros JR, Agudo A, Sanchez MJ, Gavrila D, Barricarte A, Dorronsoro M, Ohlsson B, Lindkvist B, Johansson A, Sund M, Khaw KT, Wareham N, Travis RC, Riboli $\mathrm{E}$ and Pischon T: Inflammatory and metabolic biomarkers and risk of liver and biliary tract cancer. Hepatology 60: 858-871, 2014.

22 Liu CJ, Chen PJ, Lai MY, Liu CH, Chen CL, Kao JH and Chen DS: High serum adiponectin correlates with advanced liver disease in patients with chronic hepatitis B virus infection. Hepatol Int 3: 364-370, 2009.

23 Kaser S, Moschen A, Kaser A, Ludwiczek O, Ebenbichler CF, Vogel W, Jaschke W, Patsch JR and Tilg H: Circulating adiponectin reflects severity of liver disease but not insulin sensitivity in liver cirrhosis. J Intern Med 258: 274-280, 2005.

24 Dalamaga M, Diakopoulos KN and Mantzoros CS: The role of adiponectin in cancer: a review of current evidence. Endocr Rev 33: 547-594, 2012.

25 Nepal S and Park PH: Modulation of Cell Death and Survival by Adipokines in the Liver. Biol Pharm Bull 38: 961-965, 2015.

26 Xing SQ, Zhang CG, Yuan JF, Yang HM, Zhao SD and Zhang H: Adiponectin induces apoptosis in hepatocellular carcinoma through differential modulation of thioredoxin proteins. Biochem Pharmacol 93: 221-231, 2015.

Received September 14, 2016

Revised September 23, 2016

Accepted September 26, 2016 